\title{
Black Hole Algorithm Implemented for Congestion Management in a Competitive Power Market
}

\author{
R. Ramachandran \\ Assistant professor \\ Electrical Engineering, \\ Annamalai University, INDIA
}

\author{
M. Arun \\ Assistant professor \\ Electrical Engineering, \\ Annamalai University, INDIA
}

\begin{abstract}
Transmission congestion is the major challenge in the operation of competitive power market. Sufficient transmission corridor is necessary for realization of power transaction. This paper proposes an efficient approach for transmission congestion management using the Black Hole Algorithm (BHA). Congestion is relieved by rescheduling of real power from the market clearing schedule. BHA is a recently introduced nature inspired algorithm with less number of parameters. The algorithm is easy for implementation, takes less number of iterations and tuning for a particular application. The strength of the algorithm is validated by comparing its performance with that of Particle Swarm Optimization (PSO) and Big Bang Big Crunch (BBBC) algorithms available in the literature. Modified IEEE30 and Modified IEEE-57 bus systems are taken for the simulation purpose.
\end{abstract}

\section{General Terms}

Competitive power market, black hole algorithm.

\section{Keywords}

Rescheduling, line outage, overloaded bilateral / multilateral transaction

\section{INTRODUCTION}

In a deregulated power market, generating companies (GENCOs) are producing power and sell it to the distributing companies (DISCOs). The independent system operator (ISO) is facilitating power transfer between agreed GENCO and DISCO. All agreed transactions are not always feasible due to thermal limit of lines and voltage stability limit. A transaction may be economical but unrealistic when there is no sufficient transmission corridor. Transmission congestion may be defined as some of the lines reaching their thermal limit during transaction between GENCOs and DISCOs. Transmission congestion affects the security of a power system as it leads to cascaded outage of lines in the system. Transmission congestion needs to be managed by several different ways and they are classified based on whether cost is involved or not.

i. Cost free methods:

a. By outaging the congested lines.

b. By the use of transformer taps or phase shifters.

c. Operation of FACTS devices particularly series devices.

ii. Non-cost free methods:

a. By re scheduling of generation from generators.

b. Through curtailment of loads.

In restructured power markets limitations of power transmission networks due to environmental, right-of-way (ROW) and economic problems is a big challenge. Optimal generation corresponding to minimum cost results in increased losses and threatens the stability and security of the power systems [1], [2]. Different congestion management methods suitable for different electricity markets are reported in the literatures [3]. But the thirst for still efficient and reliable method to solve this congestion management problem is endless [4]. In [5], an efficient zonal congestion management approach using Power Transfer Distribution Factors (PTDF) is discussed. Hogan follows the contract path and nodal pricing approach [6] using spot pricing theory [7] for the pool-based market. An alternative approach based on parallel markets for link-based transmission capacity rights is used by Chao and Peck [8]. A coordinating approach between generating companies and system operator for congestion management using Benders cuts is discussed by H.Y.Yamina and Shahidehpour [9].

Willingness-to-pay premium is recommended for avoiding curtailment of the agreed transactions [10]. Locational Marginal Price (LMP) signals are also used [11] for generators to relieve transmission congestion. The technique discussed in [12] combines the congestion cost and the marginal cost at each bus in a pool power model and cost minimization is achieved. For congestion relief, better utilization of existing transmission line is a suitable alternative. As such, Flexible AC Transmission Systems (FACTS) devices are also used [13]. Applications of FACTS devices, for instance, Thyristor-Controlled Series Compensator (TCSC) and Thyristor Controlled Phase Angle Regulator (TCPAR) are proposed to manage congestion rapidly and efficiently.

Work [14] proposes an OPF problem for minimum costs for both congestion and service. Relieving congestions caused by voltage instability and thermal overloads is taken in [15]. This also uses OPF which is solved by standard solvers. Line overload alleviation by rescheduling of real power generation based on relative electrical distance (RED) is introduced in [16]. But the rescheduling cost is not optimized when the generators have different cost functions. Congestion management by load curtailment [17] is done by B.K. Talukdar et al.

Congestion management by optimal real power rescheduling is suggested through optimization techniques. Evolutionary Programming (EP) approach is used to reschedule the real power generation for congestion management in [18]. Optimal congestion management in an electricity market using particle swarm optimization with time-varying acceleration coefficients (PSO-TVAC) is done by Panida Boonyaritdachochai, Chanwit Boonchuay, Weerakorn Ongsakul in [19]. Tulika Bhattacharjee and Ajoy Kumar Chakraborty have suggested the NSGAII algorithm for congestion management in a pool-based electricity market Incorporating voltage and transient stability [20]. 
Multi Objective Particle Swarm Optimization (MOPSO) method is used by J. Hazra and Sinha for cost efficient generation rescheduling and/or load shedding as a mean for congestion management [21]. S. Dutta and Singh [22] used PSO algorithm for identifying the contributing generators and optimum rescheduling of real power for managing congestion in a pool at minimum rescheduling cost. Adaptive bacterial foraging algorithm is exploited for congestion management by B.K. Panigrahi and V. Ravikumar Pandi in [23]. Venkaiah and Vinod Kumar [24] explored fuzzy adaptive bacterial foraging $(\mathrm{FABF})$ algorithm for congestion management by optimal rescheduling of powers.

In this paper, the recently developed, simple and efficient algorithm of BHA is taken for optimal rescheduling of real power for congestion management in a pool based power market. The algorithm used is easy for implementation, with less number of parameters and efficient in obtaining the global best results.

\section{BLACK HOLE PHENOMENON}

John Michell and Pierre Laplace were the first to introduce the concept of black holes in the eighteen century. They identified the absence of star by integrating Newton's law but the absence of star was not known as black hole at that time. Only in 1967, John Wheeler, an American physicist first named the phenomenon of mass collapsing or absence of star as a black hole. A black hole in space is what is left when a star or massive sized planet collapses. The gravitational power of the black hole is too high that even the light cannot escape from it. Anything that crosses the boundary of the black hole is swallowed by it and vanishes. The sphere-shaped boundary of a black hole in space is known as the event horizon. The radius of the event horizon is termed as the Schwarzschild radius. At this radius, the escape speed is equal to the speed of light, and once light passes through, even it cannot escape. The Schwarzschild radius is calculated by the following equation:

$$
R=\frac{2 G M}{C^{2}}
$$

Where, $\mathrm{G}$ is the gravitational constant, $\mathrm{M}$ is the mass of the black hole, and $\mathrm{c}$ is the speed of light. If anything moves close to the event horizon it will be absorbed into the black hole and permanently disappear.

\subsection{Black Hole Algorithm (BHA)}

Similar to the other meta-heuristics algorithms, a population of randomly distributed candidate solutions for the given problem is created. All the population-based algorithms move the individuals towards the global best solution through certain techniques. For example, mutation and crossover operations are followed in GA. In PSO, the movement of the initial solution towards the global best solution is based on the individual best and global best in each iteration.

In BHA, the evolving of the population is done by moving all the candidates towards the best candidate in each iteration, namely, the black hole and replacing those candidates that enter within the range of the black hole by newly generated candidates in the search space. The proposed BHA in this paper is more similar to the natural black hole phenomenon. In BHA the best candidate among all the candidates at each iteration is selected as a black hole. Then, all the candidates are moved towards the black hole based on their current location and a random number. The searching mechanism of BHA is as under:
A randomly generated population of solutions is taken as the initialization process. Then the fitness values of the population are evaluated and the best solution whose fitness value is the best one is the black hole. After initializing the black hole and stars, the black hole starts absorbing the stars around it and all the stars start moving towards the black hole. The absorption of stars by the black hole is formulated as follows:

$x_{i}(t)=x_{i}(t-1)+\operatorname{rand}(0,1)\left(x_{B H}-, x_{i}(t-1)\right)$

where $x_{i}(t)$ and $x_{i}(t-1)$ are the locations of the ith star at iterations $t$ and $t-1$, respectively. $x_{B H}$ is the location of the black hole in the search space. rand is a random number in the interval $[0,1] . \mathrm{N}$ is the number of stars (candidate solutions). While moving towards the black hole, a star may reach a location with lower cost than the black hole. In such a case, the black hole moves to the location of that star and vice versa. Then the BHA will continue with the black hole in the new location and then stars start moving towards this new location. In addition, there is the probability of crossing the event horizon during moving stars towards the black hole. Every star (candidate solution) that crosses the event horizon of the black hole will be sucked by the black hole. Every time a candidate (star) dies - it is sucked in by the black hole another candidate solution (star) is born and distributed randomly in the search space and starts a new search. This is done to keep the number of candidate solutions constant. The next iteration takes place after all the stars have been moved. The radius of the event horizon in the black hole algorithm is calculated using the following equation:

$$
R=\frac{f_{B H}}{\sum_{i=1}^{N} f_{i}}
$$

where $f_{B H}$ is the fitness value of the black hole and $f_{i}$ is the fitness value of the ith star. $\mathrm{N}$ is the number of stars (candidate solutions). When the distance between a candidate solution and the black hole (best candidate) is less than $\mathrm{R}$, that candidate is collapsed and a new candidate is created and distributed randomly in the search space. Based on the above description the main steps in the $\mathrm{BH}$ algorithm are summarized as follows:

\subsection{Implementation of BHA for congestion management}

Step 1: Initialize the algorithm parameters like population size, maximum number of generations and black hole.

Step 2: Each individual is a vector of the control variables. i.e. i.e. $\mathrm{Xi}=[\mathrm{VG} 1, \mathrm{VG} 2 \ldots \mathrm{VG} \mathrm{NG}, \mathrm{TP} 1$, TP2 ..TP NT, Qc1, Qc2 ....Q $\mathrm{NC}_{\mathrm{NC}}$. NP number of agents are generated by respecting the limits of control parameters.

Step 3: Calculate the fitness function values of all candidate solution by running the NR load flow.

Step 4: Determine the center of mass which has global best fitness using equation (3).

Step 5: Generate new candidates using the center of mass, particle best and global best by adding/subtracting a normal random number according to equation (2).

Step 6: Repeat steps step 2 to step 5 until stopping criteria has been achieved. 


\section{MATHEMATICAL PROBLEM FORMULATION}

The main objective of the proposed work is to find the optimal rescheduled values of active power generations from the generators so as to minimize the total congestion while satisfying the generators equality and inequality constraints. When the generation bids are submitted, congestion cost is computed using the following mathematical equations. The objective function of this congestion management problem can be written mathematically as:

$$
\min T C=\sum_{j=1}^{n g}\left(C_{k} \Delta P_{G j}^{+}+D_{k} \Delta P_{G j}^{-}\right) \quad \$ / \mathrm{hr}
$$

Where,

$$
\begin{array}{ll}
T C & \text { is the total congestion cost in } \$ / \mathrm{hr} \\
C_{k} & \text { is the incremental biding cost } \\
D_{k} & \text { is the decremented biding cost } \\
\Delta P_{G j}^{+} & \text {is the amount of active power increment } \\
\Delta P_{G j}^{-} & \text {in the generator } \mathrm{j} . \\
& \text { in the amount of active power decrement }
\end{array}
$$

\subsection{Equality constraints:}

\subsubsection{Real power balance:}

$P_{g i}-P_{d i}-\sum_{j=1}^{N}\left|V_{i}\right|\left|V_{j}\right|\left|Y_{j i}\right| \cos \left(\delta_{i}-\delta_{j}-\theta_{i j}\right)=0$

\subsubsection{Reactive power balance:}

$Q_{g i}-Q_{d i}-\sum_{j=1}^{N}\left|V_{i}\right|\left|V_{j} \| Y_{j i}\right| \sin \left(\delta_{i}-\delta_{j}-\theta_{i j}\right)=0$

$P_{g i}=P_{g i}^{c}+\Delta P_{g i}^{+}-\Delta P_{g i}^{-} \quad ; i=1,2,3 \ldots n g$

$P_{d k}=P_{d k}^{c} \quad ; k=1,2,3 \ldots . . N d$

\subsection{Inequality constraints:}

\subsubsection{Real power generation output:}

$P_{G i}^{\min } \leq P_{G i} \leq P_{G i}^{\max } \quad i=1, \ldots . n g$

\subsubsection{Reactive power generation output:}

$Q_{G i}^{\min } \leq Q_{G i} \leq Q_{G i}^{\max } \quad i=1, \ldots . n g$

3.2.3 Incremented or decremented real limit:

$\left(P_{g i}-P_{g i}^{\min }\right)=\Delta P_{g i}^{\min } \leq \Delta P_{g i} \leq \Delta P_{g i}^{\max }=\left(P_{g i}^{\max }-P_{g i}\right)$

$$
\Delta P_{g i}^{+} \geq 0 ; \Delta P_{g i}^{-} \geq 0
$$

\section{RESULTS AND DISCUSSION}

The performance of BHA algorithm in congestion management problem is tested in the modified IEEE-30 bus and the modified IEEE-57 bus systems. The modified IEEE30 bus system consists of 41 transmission lines, 24 load buses, 6 Generator buses with a base load of 283.4 MW active power and 126.2 MVAR reactive power. In the modified IEEE-57 bus system there are 50 load buses, 80 transmission lines, and

\begin{tabular}{|c|c|c|c|}
\hline $\begin{array}{l}\text { Sl. } \\
\text { No }\end{array}$ & Case & $\begin{array}{c}\text { Conditions applied in } \\
\text { the system }\end{array}$ & Test System \\
\hline 1 & Case A & Outage of line $1-2$ & $\begin{array}{l}\text { Modified } \\
\text { IEEE-30 bus }\end{array}$ \\
\hline 2 & Case B & $\begin{array}{l}\text { Load at all the buses are } \\
\text { raised by } 20 \%\end{array}$ & $\begin{array}{l}\text { Modified } \\
\text { IEEE- } 30 \text { bus }\end{array}$ \\
\hline 3 & Case C & $\begin{array}{l}2 \text { bilateral transactions } \\
\text { T1- } 20 \text { MW from bus } 9 \text { to } \\
\text { bus } 13 \\
\text { T2- } 10 \text { MW from bus } 3 \text { to } \\
\text { bus } 41\end{array}$ & $\begin{array}{l}\text { Modified } \\
\text { IEEE-57 bus }\end{array}$ \\
\hline 4 & Case D & $\begin{array}{l}2 \text { multilateral transactions } \\
\text { T1-50 MW from bus } 4 \text { to } \\
\text { bus } 15 \text { as } 20 \text { MW \& bus } \\
19 \text { as } 30 \text { MW. } \\
\text { T2- } 25 \text { MW from bus } 10 \\
\text { bus } 47 \text { as } 10 \text { MW \& bus } \\
56 \text { as } 15 \text { MW }\end{array}$ & $\begin{array}{l}\text { Modified } \\
\text { IEEE-57 bus }\end{array}$ \\
\hline
\end{tabular}
7 generator buses with a total load of $1250.8 \mathrm{MW}$ real power and 336.4 MVAR reactive power. Line data and bus data for both the test case systems are taken from the [27]. Here, four cases have been taken as shown in the table.

The different operating conditions considered for congestion management are as in table Evaluated conditions in the test case.

Table 1. Different cases considered

\subsection{Case: A}

The primary cause of transmission congestion is taken in this case. Line outage contingency screening and ranking shows that line 1-2 is the most critical one in IEEE-30 bus system. Congestion due to the outage of the line is relieved by rescheduling the power output from the generators. Performance wise BHA is better than the other two algorithms. Total congestion cost suggested by BHA is only $476.983 \$$ while it is $665.4502 \$$ by PSO and $586.2415 \$$ by $\mathrm{BBBC}$. The cost shown by BHA is much low and it is proving the strength of the algorithm.

Table 2. Optimal rescheduling power for case A

\begin{tabular}{|c|c|c|c|}
\hline $\begin{array}{c}\text { Rescheduled } \\
\text { power }\end{array}$ & $\begin{array}{c}\text { BBBC } \\
\text { Technique }\end{array}$ & $\begin{array}{c}\text { PSO } \\
\text { Technique }\end{array}$ & $\begin{array}{c}\text { BHA } \\
\text { Technique }\end{array}$ \\
\hline$P_{G 1}$ & 129.632 & 129.992 & 129.915 \\
\hline$P_{G 2}$ & 67.5414 & 62.4440 & 71.9032 \\
\hline$P_{G 3}$ & 24.7957 & 28.1494 & 24.6938 \\
\hline$P_{G 4}$ & 35.2147 & 37.8556 & 35.0047 \\
\hline$P_{G 5}$ & 21.6808 & 18.0638 & 18.0412 \\
\hline$P_{G 6}$ & 17.7766 & 20.0729 & 17.1301 \\
\hline $\begin{array}{c}\text { Congestion } \\
\text { Cost }\end{array}$ & 586.789 & 665.4502 & 476.983 \\
\hline Loss & 13.2415 & 13.1784 & 13.2884 \\
\hline
\end{tabular}


It is clear from table 3 PSO recommends for decremental change in all the generators except at generator 1 for relieving congestion. BHA and BBBC are behaving in a similar way in managing congestion as both the methods taking same pattern of incremental or decremental change. For minimum congestion cost, BHA shows relatively large change than PSO and BBBC methods at generator 2 .

Table 3. Optimal change of real power for case $A$

\begin{tabular}{|l|l|l|l|l|l|l|}
\hline \multirow{2}{*}{$\begin{array}{c}\text { 莺 } \\
\text { 总 }\end{array}$} & \multicolumn{6}{|c|}{ UP/DOWN adjustment of participating generators (MW) } \\
\cline { 2 - 7 } & $\Delta P_{G 1}$ & $\Delta P_{G 2}$ & $\Delta P_{G 3}$ & $\Delta P_{G 4}$ & $\Delta P_{G 5}$ & $\Delta P_{G 6}$ \\
\hline BBC & -8.9577 & 9.9814 & 0.2357 & 0.2147 & -0.1534 & 1.1666 \\
\hline PSO & -8.5973 & 4.8840 & 3.5894 & 2.8556 & 2.1429 & 3.4629 \\
\hline BHA & -8.6746 & 14.3432 & 0.1338 & 0.0047 & -0.7999 & 0.5201 \\
\hline
\end{tabular}

Power flow in the lines of the system under different conditions are compared in figure 1. Outage of line 1-2 results in overflow in lines 2 and 4 . The congested flow in these two lines are removed by rescheduling of generator powers. It is obvious from the figure that all the three algorithms are succeeded in congestion management.

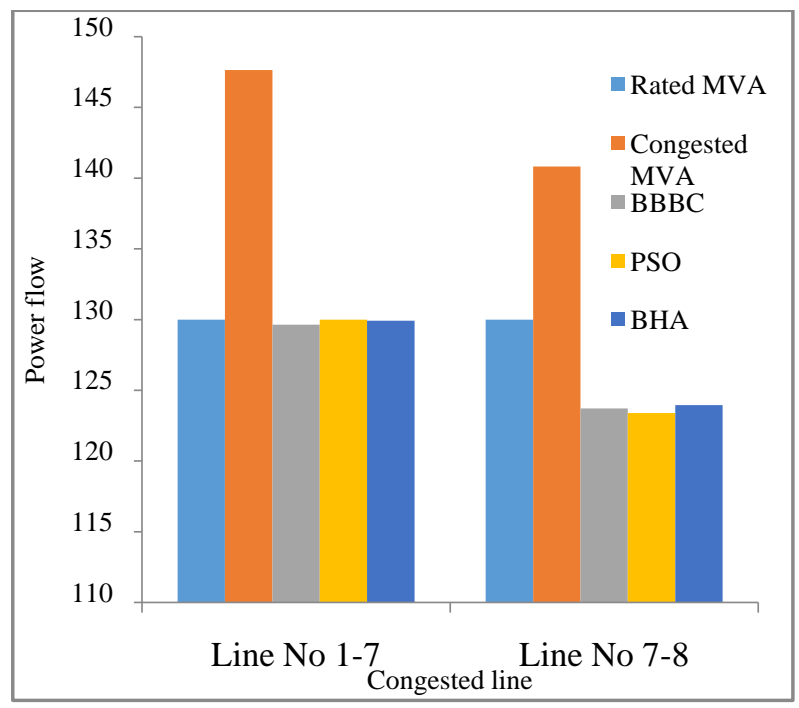

Figure 1. Power flow through the lines (Case A)

Strength of an optimization algorithm is generally analyzed by the number of times the algorithm is run for finding the global best solution. The algorithm maintains the best solution at different iterations and converged to the global best solution at the $60^{\text {th }}$ iteration. Within 100 iterations best solution is reached.

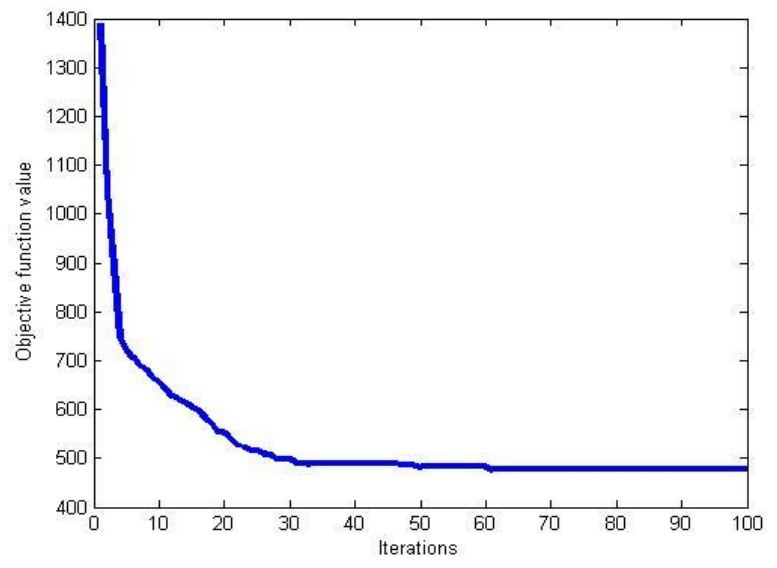

Figure 2. Convergence behaviour of BHA in case A

\subsection{Case B}

Increase in load causes transmission congestion. In this case, load at all the 24 load buses are increased by $20 \%$. The total real and reactive power demands are $340.08 \mathrm{MW}$ and 151.44 MVAR respectively. As a result, line 1 gets congested. Congestion cost occurring in rescheduling of real power by the three methods are compared in table 4. Congestion cost found by BHA algorithm is better than the costs reported by PSO and BBBC algorithms.

Table 4. Optimal rescheduling for case $B$

\begin{tabular}{|c|c|c|c|}
\hline $\begin{array}{l}\text { Rescheduled } \\
\text { power }\end{array}$ & $\begin{array}{l}\text { BBBC } \\
\text { Technique }\end{array}$ & $\begin{array}{l}\text { PSO } \\
\text { Technique }\end{array}$ & $\begin{array}{l}\text { BHA } \\
\text { Technique }\end{array}$ \\
\hline$P_{G 1}$ & 172.5337 & 190.2066 & 181.6946 \\
\hline$P_{G 2}$ & 81.0509 & 61.3884 & 73.8379 \\
\hline$P_{G 3}$ & 24.7049 & 28.6971 & 26.0898 \\
\hline$P_{G 4}$ & 37.0619 & 35.5828 & 34.9799 \\
\hline$P_{G 5}$ & 18.3775 & 18.9187 & 18.1488 \\
\hline$P_{G 6}$ & 18.3373 & 17.6376 & 17.7019 \\
\hline Congestion Cost & 1412.6 & 1487.1 & 1396.9 \\
\hline Loss & 11.9862 & 12.3512 & 12.3699 \\
\hline
\end{tabular}

In rescheduling of real power, all the three algorithms are behaving in the same manner. The change in power is decremental at all the generator buses.

Table 5. Change in power for case $B$

\begin{tabular}{|l|l|l|l|l|l|l|}
\hline \multirow{2}{*}{\begin{tabular}{c} 
莺 \\
\multirow{J}{*}{}
\end{tabular}} & \multicolumn{5}{|l|}{ UP/DOWN adjustment of participating generators (MW) } \\
\cline { 2 - 7 } & $\Delta P_{G 1}$ & $\Delta P_{G 2}$ & $\Delta P_{G 3}$ & $\Delta P_{G 4}$ & $\Delta P_{G 5}$ & $\Delta P_{G 6}$ \\
\hline BBBC & 33.9437 & 23.4909 & 0.1449 & 2.0619 & 0.4475 & 1.7273 \\
\hline PSO & 51.6166 & 3.8284 & 4.1371 & 0.5828 & 0.9887 & 1.0276 \\
\hline BHA & 43.1046 & 16.2779 & 1.5298 & -0.0201 & 0.2188 & 1.0916 \\
& & & & & & \\
\hline
\end{tabular}


For clear understanding of the congestion relief, line flow through the congested line 1-2 is depicted in figure 3. BBBC outperforms the other two algorithms of PSO and BHA in relieving the line. However, the objective of minimum cost for removing congestion is achieved only by the proposed BHA algorithm.

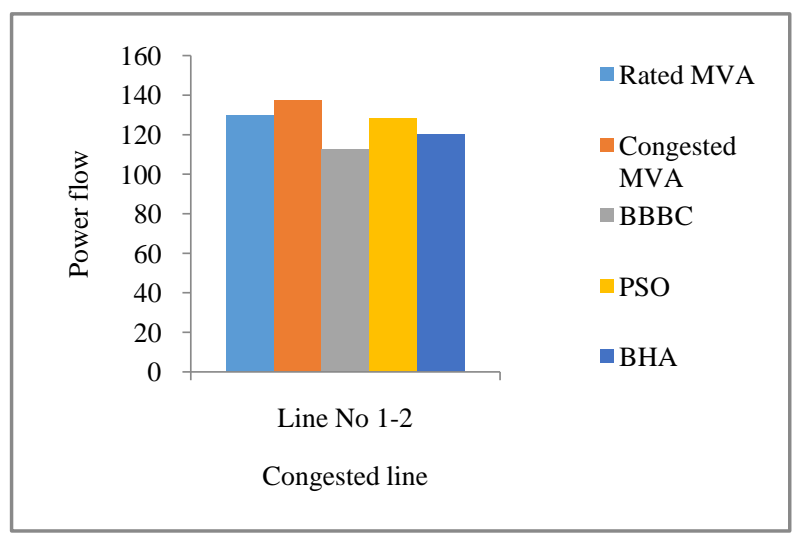

Figure 3. Power flow through the lines (Case B)

Convergence characteristic of BHA in this case is shown in figure 4 . The number of iterations taken to reach the best result is only 25 . The number of iterations taken is much encouraging and proves the efficiency of the algorithm

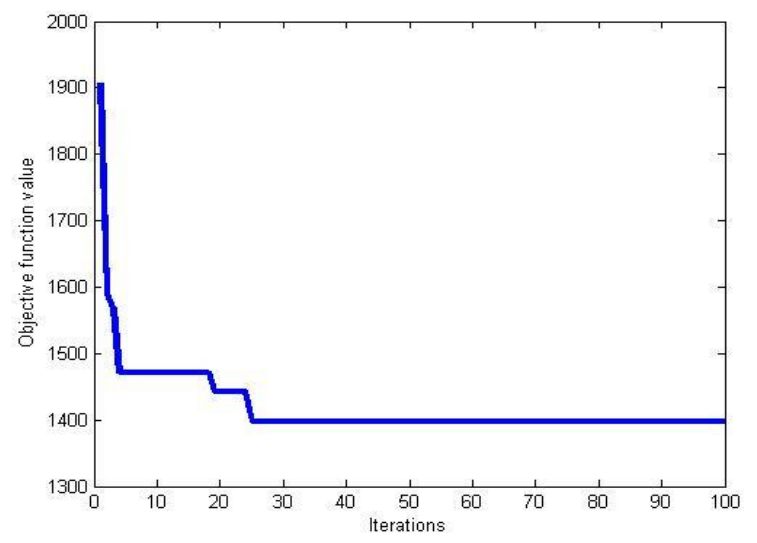

Figure 4. Convergence behavior of BHA in case B

\subsection{Case C}

In a deregulated power market, there are bilateral transactions between GENCOs and DISCOs causing overload in lines connecting them. Here, two bilateral transactions, one between buses 9 and 13 and the other one between buses 3 and 41 are taken. The farmer transaction is for $20 \mathrm{MW}$ and the later is for $10 \mathrm{MW}$. Congestion cost reported by the three algorithms is compared in table 6 . In this case also the cost suggested by the BHA algorithm is the minimum one. The saving in cost by BHA is 10054.8 \$ when compared to PSO and $437.9 \$$ to BBBC

Table 6. Optimal rescheduled power for case $\mathrm{C}$

\begin{tabular}{|c|l|l|l|}
\hline $\begin{array}{l}\text { Rescheduled } \\
\text { power }\end{array}$ & $\begin{array}{l}\text { BBBC } \\
\text { Technique }\end{array}$ & $\begin{array}{l}\text { PSO } \\
\text { Technique }\end{array}$ & $\begin{array}{l}\text { BHA } \\
\text { Technique }\end{array}$ \\
\hline$P_{G 1}$ & 156.026 & 174.831 & 151.785 \\
\hline$P_{G 2}$ & 100.000 & 99.9855 & 94.1063 \\
\hline
\end{tabular}

\begin{tabular}{|c|l|l|l|}
\hline \multicolumn{1}{|c|}{$P_{G 3}$} & 45.3448 & 46.3399 & 42.7881 \\
\hline$P_{G 4}$ & 89.7372 & 79.2741 & 90.0794 \\
\hline$P_{G 5}$ & 435.662 & 447.775 & 449.767 \\
\hline$P_{G 6}$ & 89.0122 & 85.4515 & 80.5799 \\
\hline$P_{G 7}$ & 356.719 & 339.720 & 363.709 \\
\hline $\begin{array}{l}\text { Congestion } \\
\text { Cost }\end{array}$ & 3277.70 & 3894.60 & 2839.80 \\
\hline \begin{tabular}{l} 
Loss \\
\hline
\end{tabular} & 21.7026 & 22.5781 & 22.0171 \\
\hline
\end{tabular}

The ups and downs in the rescheduled pattern of real power are illustrated in figure 5. The three algorithms follow different change in line flow pattern in congested lines after adjustment of power generation from different generators is compared in figure 6. All the three algorithms are succeeded in relieving congestion in the lines. However the algorithms are so tuned that the total congestion cost is minimal and that is why the level of relief is different for different algorithms.

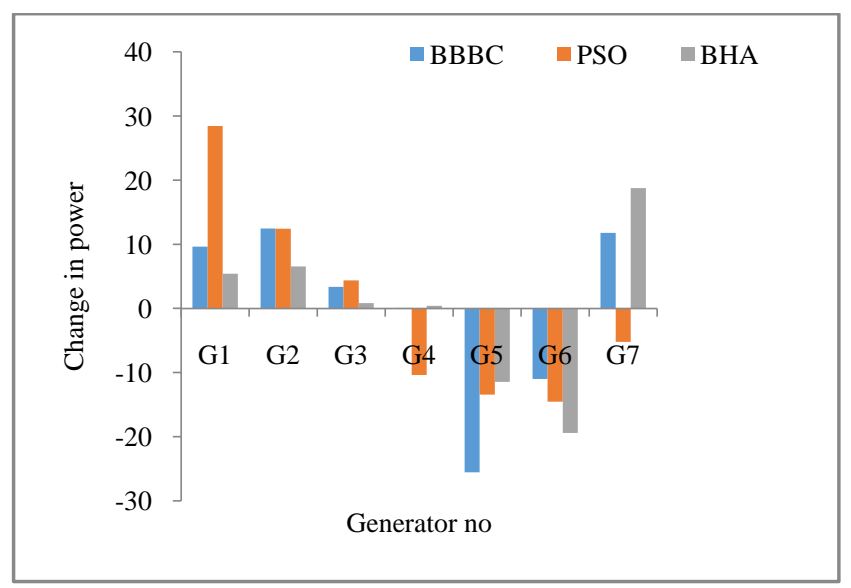

Figure 5. Amount of change in power (Case C)

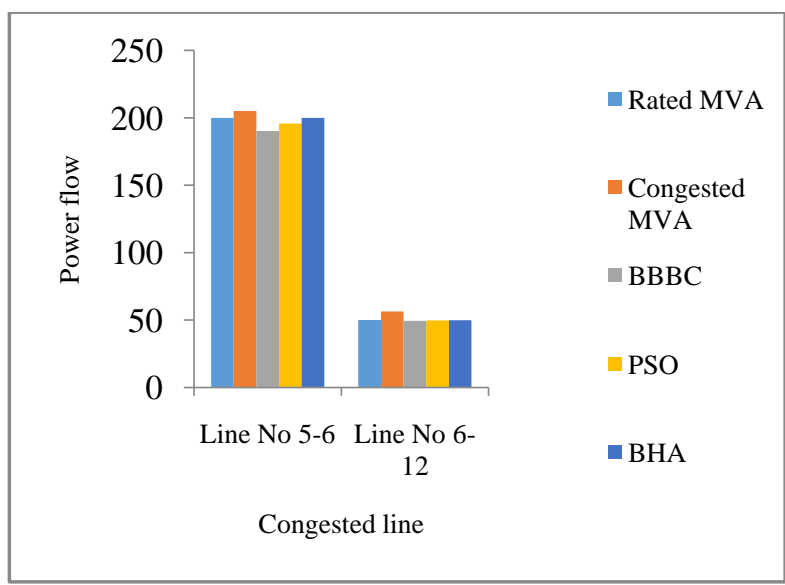

Figure 6. Amount of change in power (Case C)

Convergence quality of BHA in case $\mathrm{C}$ is plotted in figure 7 . The algorithm takes about 60 iterations to establish the global best results. 


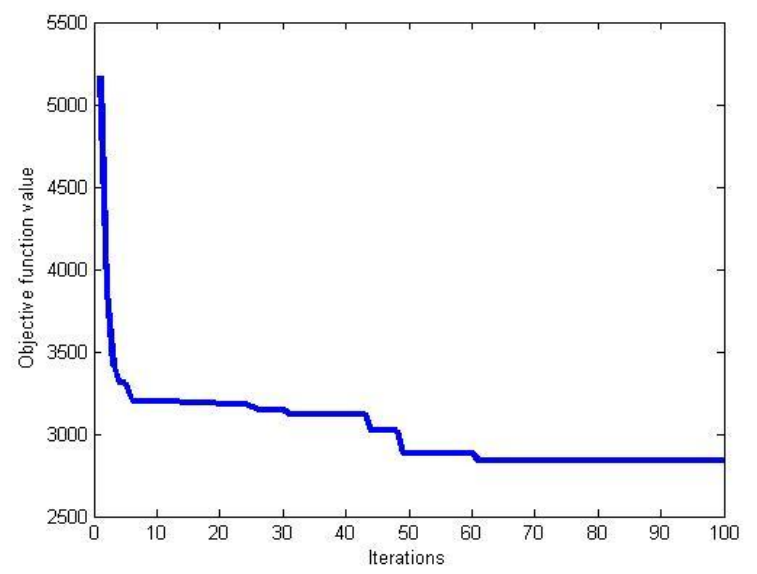

Figure 7. Convergence behavior of BHA in case $\mathrm{C}$

\subsection{Case D}

In this case, a multilateral transaction as shown in table 1 is introduced and this results in congestion of lines 8-4, 5-6 and 6-12. Real power settings corresponding to market clearing price is rescheduled for relieving congestion. The three algorithms are attempted in this task. It is clear from the table 7 that the total congestion cost achieved by the BHA is less than that by BBBC and PSO algorithms

Table 7. Optimal rescheduled power for case D

\begin{tabular}{|c|c|c|c|}
\hline $\begin{array}{c}\text { Rescheduled } \\
\text { power }\end{array}$ & $\begin{array}{c}\text { BBBC } \\
\text { Technique }\end{array}$ & $\begin{array}{c}\text { PSO } \\
\text { Technique }\end{array}$ & $\begin{array}{c}\text { BHA } \\
\text { Technique }\end{array}$ \\
\hline$P_{G 1}$ & 136.2373 & 184.762 & 154.6814 \\
\hline$P_{G 2}$ & 100.0000 & 92.6939 & 100.0000 \\
\hline$P_{G 3}$ & 87.4114 & 44.0997 & 43.6182 \\
\hline$P_{G 4}$ & 89.3565 & 79.7630 & 89.5093 \\
\hline$P_{G 5}$ & 424.5687 & 450.6397 & 444.1082 \\
\hline$P_{G 6}$ & 89.2517 & 73.3911 & 76.6197 \\
\hline$P_{G 7}$ & 354.6537 & 357.1931 & 373.3758 \\
\hline $\begin{array}{c}\text { Congestion } \\
\text { Cost }\end{array}$ & 6494.7 & 6580.9 & 6028.3 \\
\hline Loss & 30.6793 & 31.7425 & 31.1126 \\
\hline
\end{tabular}

Change in real power schedule for congestion management by the three algorithms is shown in figure 8 . For relieving the congestion in the transmission line all the algorithms are suggesting same type of change

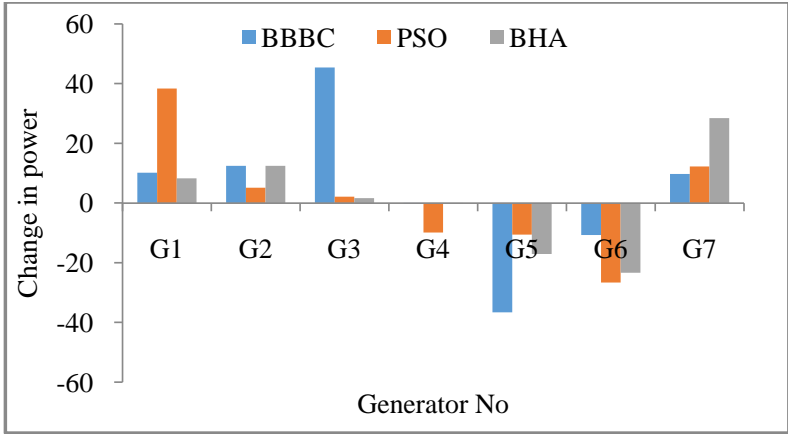

Figure 8. Amount of change in power (Case D)

A multilateral transaction as given in table 1 is considered in case D. As a result of the transaction, three lines out of 80 lines in the Modified IEEE-57 are congested. Real power generation pattern is adjusted for relieving congestion in line $8-4$, line 5-6 and line 6-12. Figure 9 shows the line flows through the congested lines before and after the congestion management. All the three algorithms are performing almost equally in the congestion management. Congestion due to the multilateral transaction is relieved by using the three algorithms.

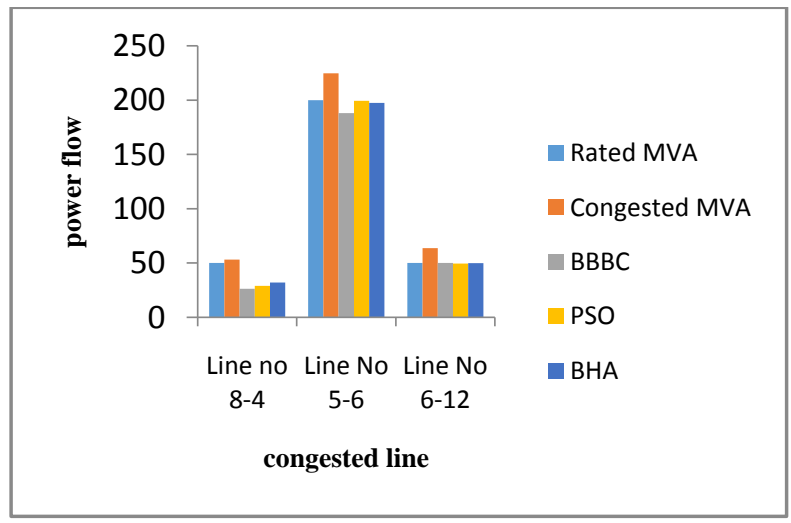

Figure 9. Power flow through the lines (Case D)

IEEE-57 bus system is a large sized power system moreover a multilateral transaction is taken as the cause for congestion. However, the BHA algorithm performs in a better manner with regard to convergence to the global best results. It is evident from the figure 10 that the algorithm is independent of the system size and is a reliable one.

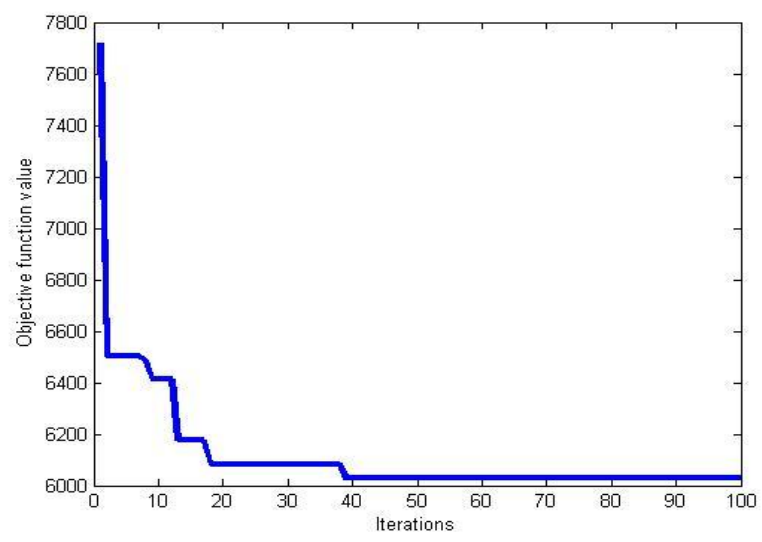

Figure 10. Convergence behavior of BHA in case D 


\section{CONCLUSION}

In this work a new nature inspired algorithm, the BHA is suggested for a power system problem. The algorithm is simple, with less number of parameters to be tuned and can be easily coded in Matlab language. Transmission congestion and availability of transmission capacity are the two key issues in operation of restructured power markets and are to be addressed. Rescheduling of power generation is followed in this work for congestion management. Three different algorithms, namely BBBC, PSO and BHA are used for congestion management through real power rescheduling. It is obvious from the numerical results that the BHA algorithm outperforms the other two algorithms in the congestion management. The performance of the BHA is tested on two test cases of Modified IEEE-30 bus system and Modified IEEE-57 bus system. Further, four different cases of congestion are taken. The BHA algorithm performs better in all the four cases and optimizes the total congestion cost.

This BHA algorithm can be of useful in other power system optimizations like economic load dispatch, optimal power flow etc. The present work can be enhanced in the future by following the real power sensitivity factors based re-dispatch of real power output from generators.

\section{ACKNOWLEDGMENTS}

The authors gratefully acknowledge the authorities of Annamalai University for the facilities offered to carry out this work.

\section{REFERENCES}

[1] Vries LJ. Capacity allocation in a restructured electricity market: technical and economic evaluation of congestion management methods on interconnectors. In: Proceedings of the 2001 IEEE Porto power tech conference.

[2] Lommerdal M, Soder L. Simulation of congestion management methods. In: Proceedings of the 2003 Bologna power tech.

[3] K.L. Lo, Y.S. Yuen, L.A. Snider, Congestion management in deregulated electricity markets, in: IEEE International Conference on Electric Utility Deregulation and Restructuring and Power Technologies 2000, 2000, pp. $47-52$.

[4] Shirmohammadi D, Wollenbarg B, Vojdani A, Sandrin P, Pereira M, Rahimi F, et al. Transmission dispatch and congestion management in the emerging energy market structures. IEEE Trans Power Syst 1998; 13(4):14661474.

[5] Ashwani Kumar, S.C. Srivastava, S.N. Singh, A zonal congestion management approach using real and reactive power rescheduling, IEEE Transactions on Power Systems 19 (1) (2004) 554-562.

[6] W. W. Hogan, "Contract networks for electric power transmission," J.Regul. Econ., vol. 4, pp. 211-242, Sept. 1992.

[7] F. C. Schweppe, M. C. Caramanis, R. D. Tabors, and R. E. Bohn, Spot Pricing of Electricity. Norwell, MA: Kluwer, 1988.

[8] H. Chao and S. Peck, "A market mechanism for electric power transmission," J. Regu. Econ., vol. 10, pp. 25-29, July 1996.
[9] Yamina HY, Shahidehpour SM. Congestion management coordination in the deregulated power market. Electr Power Syst Res 2003;65(2):119-127.

[10] R. S. Fang and A. K. David, "Transmission congestion management in an electricity market," IEEE Trans. Power Syst., vol. 4, pp. 877-883, Aug. 1999.

[11] H. Glavisch and F. Alvarado, "Management of multiple congested conditions in unbundled operation of power systems," IEEE Trans. Power Syst., vol. 13, pp. 10131019, Aug. 1998

[12] H. Singh, S. Hao, and A. Papalexopoulos, "Transmission congestion management in competitive electricity markets," IEEE Trans. Power Syst., vol. 13, pp. 672680, May 1998.

[13] Huang G, Hsieh SC. Fast textured algorithms for optimal delivery problems in deregulated environments. IEEE Trans Power Syst 1998;13 (2):493-500.

[14] Momoh JA, Zhu JZ. A new approach to optimal power flow with phase shifter. In: IEEE international conference on systems, vol. 5; 1998. p. 4794-4799.

[15] F. Jian and J. W. Lamont, "A combined framework for service identification and congestion management,", IEEE Trans. Power Syst., vol. 16, no. 1, pp. 56-61, Feb. 2001.

[16] G. Yesuratnam and D. Thukaram, "Congestion management in open access based on relative electrical distances using voltage stability criteria," Elect. Power Syst. Res., vol. 77, pp. 1608-1618, 2007.

[17] Talukdar, B. K., Sinha, A. K., Mukhopadhyay, S., and Bose, A., "A computationally simple method for costefficient generation rescheduling and load shedding for congestion management," Int. J. Elect. Power Energy Syst., Vol. 27, No. 5, pp. 379-388, June 2005.

[18] Gnanadas R, Padhy NP, Palanivelu TG. A new method for the transaction congestion management in the restructured power market. J Electr Eng, Electrika 2007;9(1):52-58

[19] Panida Boonyaritdachochai, Chanwit Boonchuay, Weerakorn Ongsakul, Optimal congestion management in an electricity market using particle swarm optimization with time-varying acceleration coefficients Computers and Mathematics with Applications 60 (2010) 1068-1077.

[20] Tulika Bhattacharjee \& Ajoy Kumar Chakraborty (2013) NSGAII-based Congestion Management in a Pool-based Electricity Market Incorporating Voltage and Transient Stability, Electric Power Components and Systems, 41:10, 990-1001, DOI: 10.1080/15325008.2013.801055.

[21] Hazra, J., and Sinha, A. K., "Congestion management using multi objective particle swarm optimization," IEEE Trans.Power Syst., Vol. 22, No. 4, pp. 1726-1734, November 2007.

[22] S. Dutta, S.P. Singh, Optimal rescheduling of generators for congestion management based on particle swarm optimization, IEEE Transactions on Power Systems 23 (4) (2008) 1560-1569.

[23] B.K. Panigrahi , V. Ravikumar Pandi, Congestion management using adaptive bacterial foraging algorithm 
Energy Conversion and Management 50 (2009) 1202 1209.

[24] Venkaiah, C., and Vinod Kumar, D. M., "Fuzzy adaptive bacterial foraging congestion management using sensitivity based optimal active power re-scheduling of generators," Appl. Soft Comput. J., Vol. 11, No. 8, pp. 4921-4930, 2011.

[25] Abdolreza Hatamlou Black hole: A new heuristic optimization approach for data clustering Information Sciences Information Sciences 222 (2013) 175-184.
[26] Mostafa Nemati, Reza Salimi, Navid Bazrkar Black Holes Algorithm: A Swarm Algorithm inspired of Black Holes for Optimization Problems IAES International Journal of Artificial Intelligence (IJ-AI) Vol. 2, No. 3, September 2013, pp. 143 150.

[27] Sujatha balaraman, N. kamaraj, transmission congestion management using particle swarm optimization journal of electrical systems 7-1 (2011): 54-70 